\title{
MORADIA SOCIAL EM COLÔMBIA: 1940-1972. A CONSOLIDAÇÃO DA HABITAÇÃO MODERNA EM MEDELLÍN
}

\section{Social Housing In Colombia: 1940-1972. The Consolidation Of Modern Housing In Medellin}

\author{
Juan José Cuervo Calle \\ Universidad Pontificia Bolivariana, Medellín \\ juan.cuervoc@gmail.com
}

\begin{abstract}
Resumo
Este texto aborda um panorama geral da habitação social moderna em Medellín Colômbia entre 1940 e 1972, marco temporal que evidencia dois momentos importantes: o período no qual a moradia de interesse social é fortemente influenciada pelas correntes da arquitetura moderna, e o começo de um processo que tornaa habitação para um bem compreendido como mercadoria. Evidencia-se a importância das instituições estatais na consolidação da habitação eas causas pelas quais o mesmo Estado se converteu, de agente produtor de habitação,emum Estado facilitador. Estes aspectos gerais se contextualizam na cidade de Medellín, para compreender como os processos da consolidação na habitação de interesse social moderna do país se inserem em um contexto particular.
\end{abstract}

\section{Palavras chaves}

Habitação social moderna, Habitação como mercadoria, institucionalidade.

\begin{abstract}
This paper discusses an overview of modern social housing in Medellin Colombia between 1940 and 1972 timeframe which demonstrates two important moments: the period in which the housing of social interest is strongly influenced by the currents of modern architecture, and the beginning of a process that housing makes for a well understood as a commodity. Highlights the importance of state institutions in the consolidation of housing and the reasons why it became the State of producer of housing in a State facilitator. These general issues are contextualized in the city of Medellin, to understand how the processes of consolidation in the social housing modern country fall in a particular context.
\end{abstract}


Modern housing, Housing as a commodity, institutions.

\section{Introdução}

Atualmente não é desconhecido que existem graves crises em matéria de moradia, não só na Colômbia, mas em toda a América Latina. As necessidades básicas da cidade, principalmente a habitação, atualmente atendem de maneira precária as necessidades da população latino-americana, reflexo deste é o aumento acrescentado de bairros marginais e as extensões de miséria nas periferias das cidades.

O processo de expansão urbana e de industrialização das principais cidades na Colômbia está enquadrado em padrões comuns que muitas cidades apresentam na América Latina, geralmente, à luz das condições de desenvolvimento capitalista: deslocamento da população do campo às cidades - tendo como consequência o abandono dos cultivos para o mero consumo, assim como o desequilíbrio entre as relações do campo e a cidade -, formação de uma rede urbana truncada e desarticulada, desnível entre o fraco desenvolvimento das forças de produção e a acelerada concentração espacial da população (...) (Singer, 1995). Temos como resultado, um solo que é disputado por inúmeros usos pautados pelas regras capitalistas, fundamento da propriedade privada do solo. Nesta disputa, a demanda do solo urbano para fins de habitação contende concomitantemente pelo melhor acesso aos serviços urbanos: água, esgoto, escolas, comércio, telefone, entre outros equipamentos regulados pelos mecanismos do mercado; inserindo a moradia no comércio formal como uma mercadoria, acentuando a valorização das áreas bem servidas (Singer, 1978; em Maricato 1979) e segregando os setores mais carentes; afastando a habitação da sua concepção como objeto social, cultural e estético, aspectos que têm implícitos elementos de dignidade, direito e habitabilidade.

No processo de modernização das cidades latino-americanas, a rápida expansão do número de seus habitantes levou a escassez do solo a níveis críticos dificultando o acesso aos serviços básicos e encarecendo a habitação a condições inacessíveis, relegando a população mais pobre. Assim começou na maioria das cidades ações de densificação,as quais, somadas ao afã de alcançar metas satisfatórias no déficit habitacional, derivadas das migrações rurais às cidades, levou à habitação, especialmente à de interesse social -, a um processo de barateamento alterando 
aspectos técnicos, espaciais, ambientais (em termos de relação com a cidade) a níveis não satisfatórios para a habitabilidade humana.

A habitação social moderna latino-americana, geralmente caracterizada por ótimas condições espaciais, sofreu neste contexto uma mudança como mercadoria, que trouxe um decaimento na qualidade arquitetônica, assim como a queda das instituições estatais encarregadas da produção habitacional de interesse social; as principais cidades colombianas não foram alheias a este processo, como é nosso caso, a cidade de Medellín.

Este texto é desenvolvido em duas partes. Aprimeira aborda umapequena contextualização da habitação social na Colômbia entre 1940 e 1972, marco temporal no qual a moradia de interesse social é fortemente influenciada pelo movimento moderno,se tornando depois,em meados dadécada de 1970, um bem compreendido como mercadoria; aqui se explicamas preocupações causadas pelas migrações rurais às principais cidades, que tiveram como consequência um elevado déficit habitacional.

A segunda parte apresenta o caso da cidade de Medellín organizado em doisitens. O primeiro expõe as bases para a consolidação da habitação social moderna por meio de dois projetos para o desenvolvimento urbano de Medellín: a proposta do "Plan para El Ensanchamiento Futuro de La Ciudad", de 1890, e o "Primer Plano de Medellín Futuro", desenvolvido em 1913. O segundo item ilustra a produção da habitação social moderna em Medellín entre 1940 e1972, período no qual foi fundamental o trabalho dos urbanistas Paul Lester Wiener e José Luis Sert, os quais trazem à Medellín as bases dos princípios definidos no Congresso Internacional de Arquitetura Moderna CIAM em 1933 por meio do Plano Regulador para a cidade. Da mesma forma se fala do aporte do Instituto de Credito Territorial (ICT) na produção de habitação moderna até que, derivada das dificuldades econômicas e sócias do país, começou umaprodução de habitação completamente descontextualizada e de má qualidade tanto ao interior das casas quanto urbana.

\section{Panorama geral da habitação social na Colômbia: 1940-1972}

Na Colômbia a partir de 1940 acontece uma confluência de situações políticosociais e econômicas na ordem nacional e internacional que indicam direcionamentos - das formas e ações do Estado Colombiano - para o andamento da habitação social a partir da segunda metade do século XX. Começa-se a se tornar evidente o impulso governamental para a criação de instituições que diretamente apoiassem a produção de moradia social: o "Banco Central Hipotecario" (BCH), a "Caja de Credito Agrario, 
Industrial y Minero" a "Caja de Vivienda Militar" e o "Instituto de Credito Territorial"(ICT); sendo este último o mais importante durante a segunda década do século XX na construção, produção e financiamento de habitação social na Colômbia. Da mesma forma, convergem uma série de missões internacionais como um dos aportes mais importantes para a consolidação da habitação moderna.

Embora muitas tenham sido as instituições que intervieram e aportaram na produção, construção e financiamento de habitação social na Colômbia, foi sem dúvidas o Instituto de Credito Territorial o que mais protagonismo teve neste sentido. O ICT foi estabelecido em 28 de janeiro de 1939 com o decreto legislativo 200, orientado inicialmente para o fomento da habitação rural e elevar a qualidade de vida da população camponesa. Depois, com a expedição da lei 46 do mesmo ano, se impulsionou a construção de moradias agrárias higiênicas, ficando a cargo do Instituto recém-criado (Monsalve, 1954). Em 1942 com o decreto 1549 foram abertas as "Seccionales de Vivienda Urbana" (SVU) para tentar dar cobertura à forte demanda das ondas de imigrantes que chegavam às principais cidades. Assim, por meio do ICT se deu um giro que correspondeu à mudança de um país rural a um país de cidades (Fique 2006). Neste mesmo ano - 1942 -, por meio do decreto 380, o governo nacional ditou medidas na busca de fomentar a indústria da construção, assim como o melhoramento da moradia popular existente por meio de recursos do "Ministerio de Hacienda" e "Crédito Público", para o fomento dos chamados "Barrios Populares Modelos" como unidades de moradiadotadas de serviços comunitários, regulamentando a sua construção.

Entre 1942 e 1972 foi o momento onde as principais cidades colombianas tiveram o processo de urbanização de maior intensidade, período considerado como a época do crescimento urbano, derivado da bonança dos preços do café alcançando os ritmos mais altos da economia do pós-guerra. Entre 1940 e 1950, junto com o recém-criado ICT, foi fundamental a participação da indústria como produtora de moradia social. Foram muitos os bairros obreiros construídos pelas empresas industriais nas imediações das fábricas, tanto a participação de entidades de natureza caritativa como fundações e sociedades sem fins lucrativos. Neste contexto, também se teve a ação de cooperativas obreiras e profissionais independentes. Em todos estes casos a norma urbana, dificilmente evidente, operava por concorrência de saberes e boas doses de sentido comum (INURVE 1996: 275). Na maioria dos casos se aplicaram os princípios técnicos e científicos do Movimento Moderno da arquitetura e do urbanismo. 
A década de 1950 é considerada o momento da modernização do setor agropecuário e o arranque do desenvolvimento capitalista, incluindo o setor da construção. Embora este panorama fosse positivo para alguns setores da economia, surgiam novos problemas: a concentração da propriedade rural no campo, a expansão da fronteira agrícola, desemprego; e, sobretudo, as migrações rurais pelas quais a população camponesa fugia da violência gerada pelas diferenças partidárias entre liberais e conservadores (Bejarano 1978). O acelerado crescimento urbano derivado destes problemas motivou as entidades municipais a produzir normas que permitissem "organizar" as cidades, pelo qual, foi fundamental a cooperação internacional para a introdução de ditos regulamentos, determinados pelos estatutos da planificação moderna. Assim, o setor da habitação social, adotou neste período fortes influências da arquitetura moderna, especialmente das ingerências do IV congresso da CIAM em 1933. Ao arredor deste panorama, se iniciou o processo na economia de passar da regulação privada na produção de habitação à intervenção particular do Estado.

O assunto era então como incrementar a produtividade de moradia para resolver o problema de habitação e como reduzir os custos de produção para que a população pudesse ascender a fim de pagar sua nova aquisição por parte do ICT. A atuação dos governos deveria girar em torno de três temas: a construção de moradia diretamente pelo Estado, o estabelecimento de normas mínimas para a construção e as leis de urbanização (Fique, 2006: 29). Para conseguir adiantar estes intuitos e alcançar a modernização das cidades, foi fundamental a participação estrangeira, tanto de instituições privadas, quanto governamentais; pelo qual este período é considerado o estágio das missões internacionais, as quais foram desenvolvidas no marco do "Frente Nacional" (FN) (1958-1974).

O Frente Nacional tem os seus antecedentes no governo militar do "Teniente General" Gustavo Rojas Pinilla, quem assumiu a presidência depois de um golpe militar contra o governo do presidente Laureano Gómez Castro em 1953. Este golpe de Estado, até 1958, foi uma saída que o governo encontrou para pacificar o país em meio de uma onda de violência causada pelas diferenças partidárias entre liberais e conservadores. Estes partidos políticos, com o fim de recuperar o poder, chegaram a um acordo onde alternaram o mandato durante 16 anos, equivalentes a quatro períodos presidências; o acordo se chamou Frente Nacional. No âmbito da politica internacional, este acordo alinhou a Colômbia com os Estados Unidos por meio da Aliança para o Progresso, modelando muitos de seus objetivos no contexto da Guerra 
Fria (Palacios e Safford, 2006: 611). O Frente Nacional seria o fato político mais relevante e de maior impacto na segunda década do século XX em muitos dos âmbitos políticos e econômicos do país, e também no desenvolvimento de inumeráveis projetos de habitação social na Colômbia.As missões internacionais: Kemmerer, Lebret, Currie e Cepal foram desenvolvidas no contexto do Frente Nacional; embora este seja um tema que possa ser ampliado em outro contexto, podemos indicar algumas generalidades.

Tanto a consolidação institucional quanto as missões internacionais, foram fundamentais para a concretização da casa moderna, especialmente a de interesse social. Na década de 1950, a produção de habitação por parte do ICT marcou a moradia em termos de crescimento quantitativo tentando responder ao crescimento intenso da população nas cidades derivado das migrações rurais para os principais centros urbanos. Neste sentido, o aporte das missões internacionais depois de 1960 logrou qualificar a habitação, já que a verificação das metas quantitativas em si mesmas não geravam melhoras nas formas de vida da população. De tal forma, um dos principais aportes das missões, e a introdução da planificação urbana a partir de estudos científicos e não desde a arbitrariedade ou o sentido comum dos seus mandatários. As missões lograram conceber a habitação em um contexto mais amplo: tratou-se de entender a moradia como um fato complexo, - não como um fenômeno físico desconexo - que deve ser posto em um contexto mais amplo no urbano com olhares sociais, culturais, políticos e econômicos. As conclusões dos estudos e diagnósticos internacionais permitiram aos governos nacionais e locais, a constituição e aplicação de normas para uma melhor regulamentação das cidades, e o melhoramento institucional dedicado à produção e financiamento de habitação. Desde o ponto de vista técnico, as missões também permitiram impulsionar procedimentos de construção repetitivos em massa concebidos na era maquinista do modernismo europeu para o barateamento da habitação, mas sem deixar de lado aspetos humanos vinculados à moradia. De tal forma, se permitiu o acesso a este bem para a população menos favorecida.

A década de 1960 foi, um período muito movimentado tanto no planejamento urbano, quanto na construção de habitação social. Porém, não só na Colômbia mas em toda América Latina, derivado da aceleração na urbanização e do crescimento populacional, se incrementou o déficit habitacional e os problemas de habitação em geral. Concluiu-se que uma boa planificação, ainda desde a experiência internacional, não é o suficiente para acrisolar as cidades, já que o seu desarranjo provém de uma 
estrutura econômica injusta (Singer, 1973: 79). Portanto os mecanismos para enfrentar a este assunto, deviam superar o âmbito do físico-espacial e se enquadrar em um processo global para o desenvolvimento.

Para a década de 1970 a habitação na Colômbia chegou a uns de os seus piores momentos. Como consequência do fracasso definitivo da Reforma Agraria proposta no marco de Frente Nacional (1961), pois as áreas rurais de maior desenvolvimento econômico se converteram em espaços de forte conflito social. A disputa pelos territórios que produziam divisas - cocaína, petróleo e ouro, principalmente-, foram ocupados por forças armadas ilegais como paramilitares, guerrilhais e narcotráfico, as quais encontraram respaldo em políticos clientelistas, pecuários, e as próprias forças militares. Esta situação, completamente agravada nesta década, produz alta mobilidade geográfica da população camponesa, fragilidade nas relações sociais dos indivíduos, inseguridade nos direitos de propriedade pelo deslocamento forçoso, precário aceso da população aos centros de mercado e altos níveis de violência com um elevado número de mortes. Esta situação ocasionou o deslocamento da população rural principalmente para as cidades, fenômeno que tem sido particularmente agudo desde então.

A partir de 1972 o Estado priorizou, em detrimento a sua preocupação causada pelas migrações rurais, a reforma agrária falida nos governos anteriores e a atenção do déficit habitacional dos anos 1950 e 1960; um problema de desenvolvimento econômico - com a concentração de recursos no financiamento da construção - , que ficou acima da dimensão social e cultural do problema (Fique, 2006: 62). O governo acreditava que com este direcionamento podia dar resposta à difícil realidade que deviam afrontar as cidades ante a elevada migração rural com todos os problemas que esta situação envolvia (Ceballos, 2008: 128). Assim, o "problema" da habitação se desprendeu definitivamente da sua dimensão sociocultural, se enquadrando na perspectiva do desenvolvimento da economia.

Na década de 1970, (somado aos problemas de violência sofridos no país), o estado expressou a sua incapacidade de atender o déficit habitacional pelos altos custos das operações estatais centralizadas e pela pouca participação do setor privado neste processo. Além disso, para este período, o ICT se encontrava completamente burocratizado e politizado com uma produção de habitação de baixa qualidade completamente afastada daquela fabricada entre 1950 e 1960 . O ICT repetia indiscriminadamente os projetos de habitação sem importar as condições climáticas e culturais do lugar, administrava de maneira ruim o subsídio e planejava 
desordenadamente os processos internos. Além disso, o sistema principal de financiamento por parte do Estado UPAC (Unidad de Poder Adquisitivo Constante), se converteu na dor de cabeça de grande parte dos beneficiários por causa dos elevados pagamentos mensais, assunto que levou à quebra o ICT. Estes acontecimentos somados a outros mais, criaram no imaginário coletivo da população um Estado inviável e incapaz de atender os cidadãos mais pobres.

\section{A consolidação da habitação social moderna em Medellín}

Depois de avaliado um panorama geral da habitação social na Colômbia, vamos agora contextualizar o problema no caso particular da cidade de Medellín. Neste caso, a consolidação da casa moderna a partir de 1940, data considerada como ponto de partida deste processo, tem importantes antecedentes formulados no início do século $X X$. Apesar de que nosso período de interesse não está estabelecido a partir deste momento, é importante conectar consideráveis fatos acontecidos em termos urbanos neste período com o problema de nosso caso. Neste sentido, o presente item pretende expor o desenvolvimento da habitação social moderna em Medellín e como esta pouco a pouco foi se convertendo em uma mercadoria derivado do mercado capitalista, afastando-se dos legados modernistas da arquitetura -especialmente da CIAM de 1933 - e das missões internacionais ocorridas no panorama nacional já ilustrados. A periodização da habitação social em Medellín é mais ou menos coincidente com o processo desenvolvido na primeira parte com relação ao panorama nacional. Em Medellín entram em cena,cedo ou tarde, tanto instituições quanto novos atores que permitem o adiantamento da habitação social moderna na cidade.

A habitação social especificamente em Medellín, sem dúvidas, foi concentrada, destacada e consolidada a partir de 1940, porém, este momento de grande produção de habitação social tem suas bases desde a última década do século XIX. A emergente elite intelectual, política e econômica derivada da atividade aurífera e cafeeira desde a segunda década do século XIX, converteu Medellín, no início do século $X X$, na segunda cidade mais importante de Colômbia, depois da capital Bogotá. Os empreendedores comerciais do momento planejaram balizar o progresso da cidade desde diferentes âmbitos, entre eles, o urbano e arquitetônico. Assim, foi iniciado, a partir de 1890, um processo de renovação urbana em resposta às necessidades da nova burguesia dominante - entre elas a habitação. A discussão de uma nova cidade por parte das elites deu início a repertórios, formas e proposições com relação ao urbano, iniciando um dos processos mais interessantes que a tornaram Medellín uma 
cidade que atualmente se apresenta à América Latina e ao mundo como objeto e tema de discussão em relação à renovação urbana. Podemos apresentar o desenvolvimento da habitação social em Medellín em dois estágios relacionados a situações e acontecimentos concretos apresentados a seguir.

\section{As bases para a produção de habitação social moderna em Medellín: 1890-} 1940

Este período corresponde a duas respostas fundamentais para 0 desenvolvimento urbano de Medellín: a proposta do "Plan para El Ensanchamiento Futuro de La Ciudad", de 1890, e o "Primer Plano de Medellín Futuro", desenvolvido em 1913. Porém, duas décadas antes da primeira proposta, novos profissionais formados na Europa chegaram a Medellín (entre médicos e engenheiros principalmente), e estabeleceram representações espaciais seguindo propostas higienistas, mas sem um modelo urbano representativo claro; assim a cidade continuou crescendo desordenadamente com abusos e arbitrariedades tanto estatais como privadas até o inicio do século $X X$.

O plano para o "Ensanchamiento Futuro de La Ciudad", sem deixar de lado as formulações e expressões camponesas próprias derivadas da época(fig. 1), se apresenta com certa influência do modelo haussmanniano, proposta em voga não só na Colômbia, mas também em muitas cidades latino-americanas que apresentavam processos de urbanização similares. Esta iniciativa se apresenta pela municipalidade com o intuito de controlar o crescimento anárquico da cidade, o domínio dos interesses privados e a redução da especulação dos terrenos por meio dos chamados três princípios diretores do urbanismo moderno: circulação, beleza e higiene, mas que na Colômbia adotaram o nome de "movimiento, hermosura y salubridad" (Gonzáles, 2007:152). Foram duas as iniciativas apresentadas por engenheiros locais neste primeiro projeto: a primeira ideia se mostrou com uma influência direta norteamericana levada à cabo pela "commission's Plan" em Nova York para o traçado urbano de Manhattan no início do século XIX; e a segunda, foi inspirada em vários exemplos desenvolvidos na Europa principalmente em Madrid e Barcelona. Ideias que fundamentaram as bases para a proposta do "Primer Plano de Medellín Futuro". 


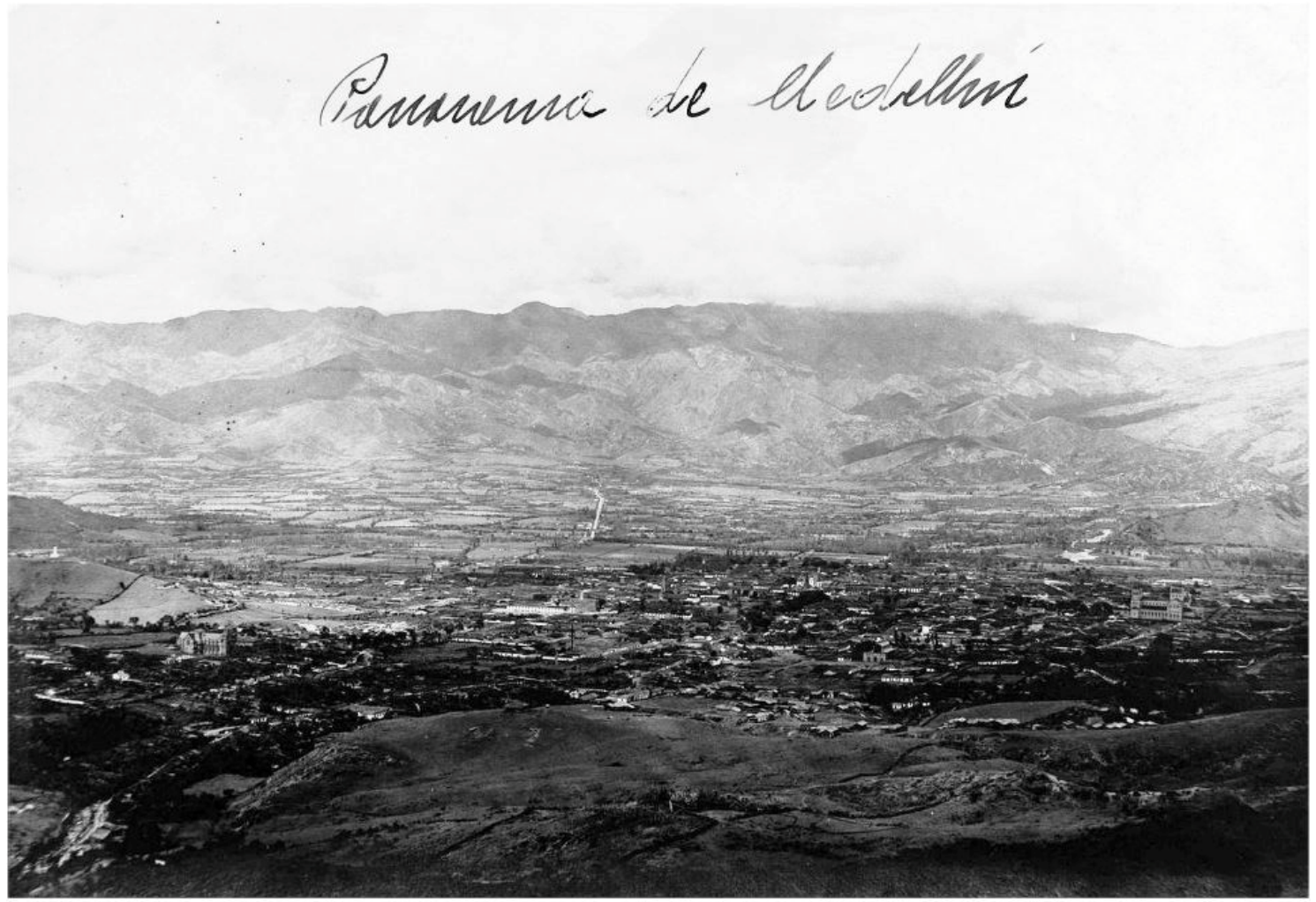

Figura 1. Medellín, cidade rural 1913. Fonte: Biblioteca Pública Piloto de Medellín para América Latina. Fonte: Fotógrafo Ángel Hernández Hernández

Em 1913 a Municipalidade de Medellín convocou um concurso público: o "Primer Plano de Medellín Futuro" (fig. 2)com o objetivo de premiar a ideia que melhor representasse a Medellín no futuro. A proposta ganhadora deveria atender às exigências de uma cidade moderna que satisfaria os requerimentos do progresso e higiene definidos na primeira proposta de 1890. Posterior a uma discussão de quase três anos, declarou-se um projeto ganhador composto por um grupo de engenheiros locais; resultado que estava longe do modelo Haussmanniano projetado na primeira iniciativa do "Ensanchamiento Futuro de La Ciudad". Esta proposta de Medellín futuro, se aproximava à visão positivista e cientificista que propôs Idelfonso Cerdá para Barcelona em 1860 e a funcionalidade do traçado urbano de Berlin realizada por Hobrecht em 1862 (Gravagnuolo, 1998: 56 em Gonzáles, 2007: 153-154). Proposta que para 1914 sofreu fortes reações opositoras reconhecendo certa inocência na sua concepção (Gonzáles, 2007: 155). Embora o plano de Medellín futuro não se materializou em toda a sua dimensão, apesar dos esforços da Municipalidade por reordenar e controlar o crescimento que seguia de maneira incontrolada na cidade, houve importantes obras como a reorganização do centro e a definição de eixos que começaram a estruturar a cidade; que hoje servem como um importante referente para os estudos urbanos na Colômbia. 


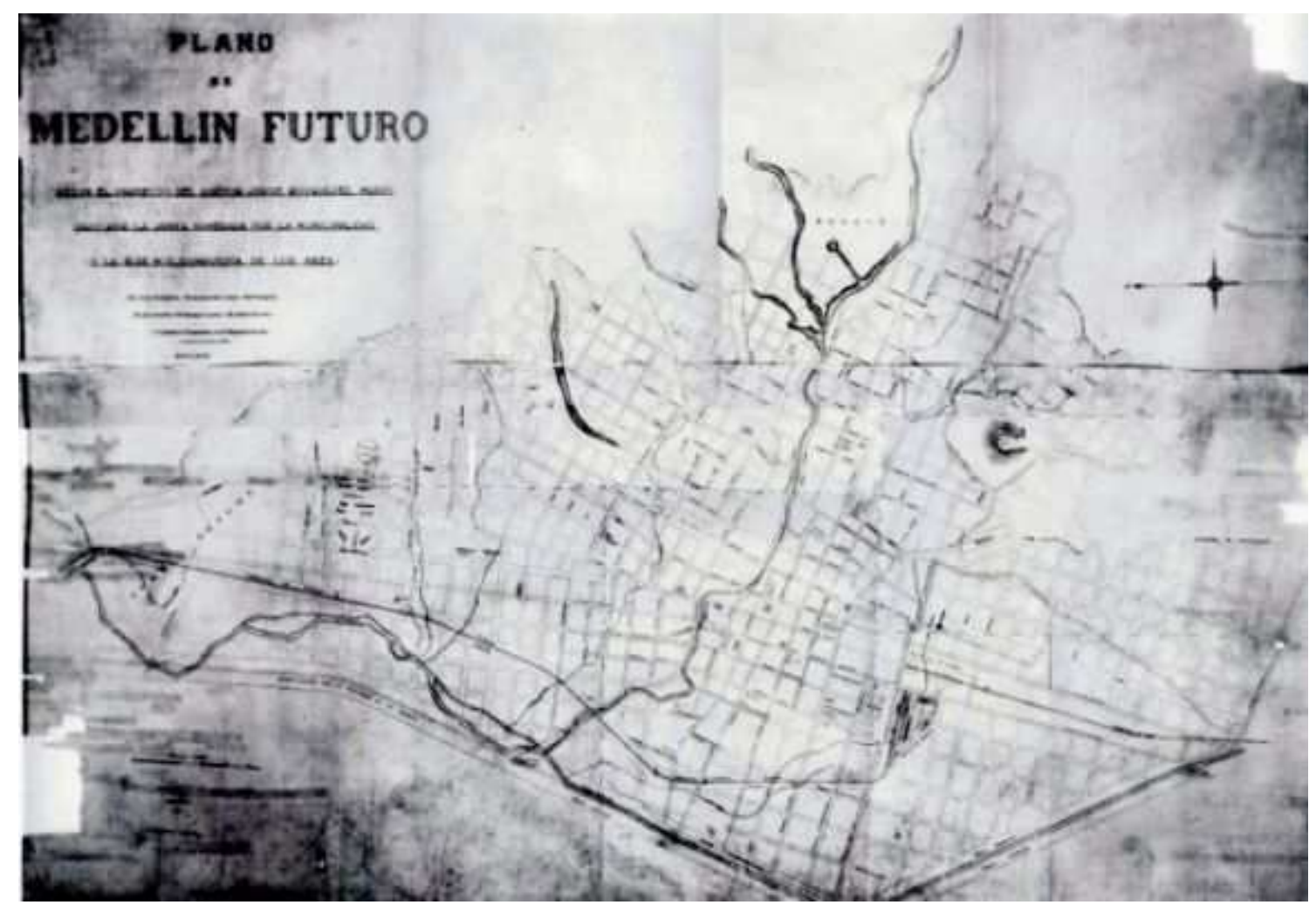

Figura 2. "Primer Plano de Medellín Futuro" 1913.

Fonte: "Ágora, Universidad Nacional de Colombia". Galeria de imagens.

Tanto na proposta do plano para o "Ensanchamiento Futuro de La Ciudad" como o "Primer Plano de Medellín Futuro", a higienização orientou as bases da proposta: regulamentaram-se aspectos como a abertura e pavimentação de vias, o aqueduto, o esgoto, "um cemitério para pessoas pobres", banhos e banheiros públicos, instalação de lavanderias municipais e fontes sanitárias. Normalizou-se também aspectos como a construção de praças, ruas e avenidas; a construção de campos de recreio para crianças, novos edifícios comerciais, de escritório e institucionais, de caráter nacional, assim como a construção de um palácio de governo, universidades e hospitais, entre outras edificações. Em termos de habitação se propôs a construção de novos bairros residenciais com "casas particulares de estilos simples, modernos e elegantes" (Betancur, 1925: 287-288), sem um modelo normativo a seguir, mas como resultado do bom senso e o saber popular coletivo, de alguns critérios profissionais, de propostas trazidas pela engenheira por poucas pessoas, assim como de algumas leis herdadas dos colonizadores espanhóis.

Nesta primeira etapa, a moradia de caráter social não era pensada de maneira prioritária para a nova cidade em crescimento, mas resulta interessante conhecer estas duas propostas já que são as que abrem as portas para a seguinte etapa na 
produção de habitação social, especificamente de características modernas na cidade de Medellín.

\section{A produção da habitação social moderna em Medellín: 1940-1972}

A experiência das propostas de Medellín Futuro permitiu a possibilidade de novas maneiras de pensar a cidade, e, assim, novos protagonistas para começar uma nova fase no desenvolvimento urbano. Este período (1940 - 1972), estárelacionado com vários fatores: o "Plano Regulador" que seguiu os princípios definidos pelo Congresso Internacional de Arquitetura Moderna (CIAM) em 1933, o impacto das missões internacionais tanto na normatividade urbana quanto na criação e distribuição de subsídios para as famílias mais pobres e a criação de instituições estatais para a produção, construção e financiamento de habitação social.

Foram especificamente os urbanistas Paul Lester Wiener e José Luis Sert, da empresa Town Planning Associates de New York contratados pela Municipalidade, para a realização do "Plan Regulador de Medellín". Depois de quase dez anos de discussão, em 1948 a companhia Wiener y Sert formulou um projeto para sedesenvolver em várias etapas. Considerou-se inicialmente análises e conhecimento das condições da cidade, elaboração de um anteprojeto chamado "Plan Piloto" (fig. 3), elaboração de um Plano Diretor (o Plano Regulador) e finalmente a execução da proposta (Schnitter 2003). Este projeto pretendia principalmente dotar a cidade de instrumentos normativos que permitiriam "ajustá-la" segundo as propostas do Plano Diretor.

Medellín no final da década de 1940 apresentava um panorama desalentador com inumeráveis problemas de circulação, mobilidade, uso do solo, carência de zonas verdes, especulação de terrenos, dentre outros; o Plano Regulador pretendia solucionar estas dificuldades refletidas no "Plan Piloto" mediante a designação das quatro funções básicas da cidade propostas pelo CIAM: habitar, trabalhar, recrear-se e circular. 


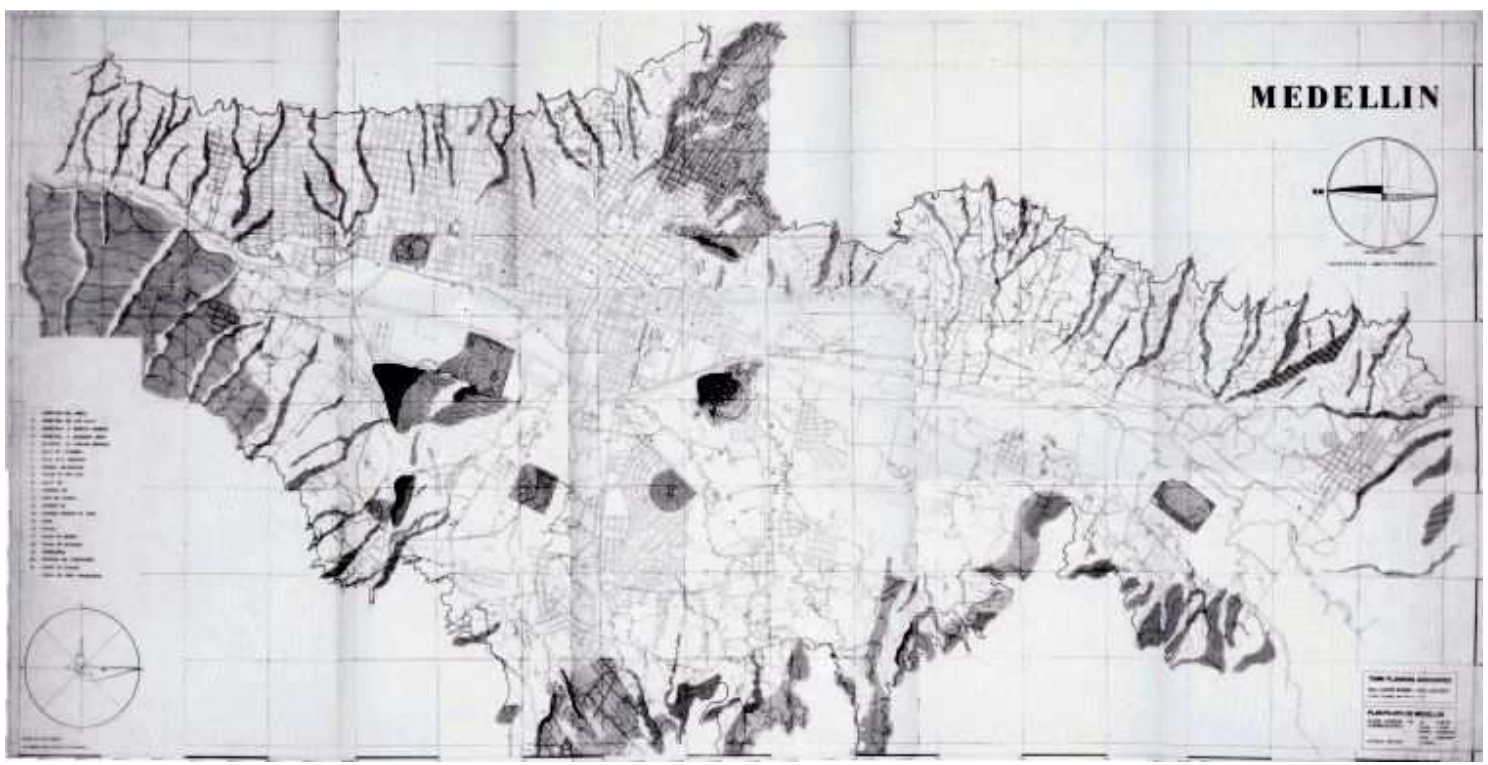

Figura 3. Proposta do "Plan Piloto" para Medellín -Wiener e Sert.

Fonte: Ágora, Universidad Nacional de Colombia". Galeria de imagens.

O "Plan Piloto" estabeleceu um olhar regional e metropolitano em diversas escalas, definindo diretrizes principalmente sobre os usos do solo, planos viários, um centro cívico, áreas verdes e principalmente de nosso interesse, um novo conceito de "Unidade Vicinal" (UV) (fig. 4) como módulo para as novas áreas residenciais que se diferenciaram dos bairros tradicionais existentes.

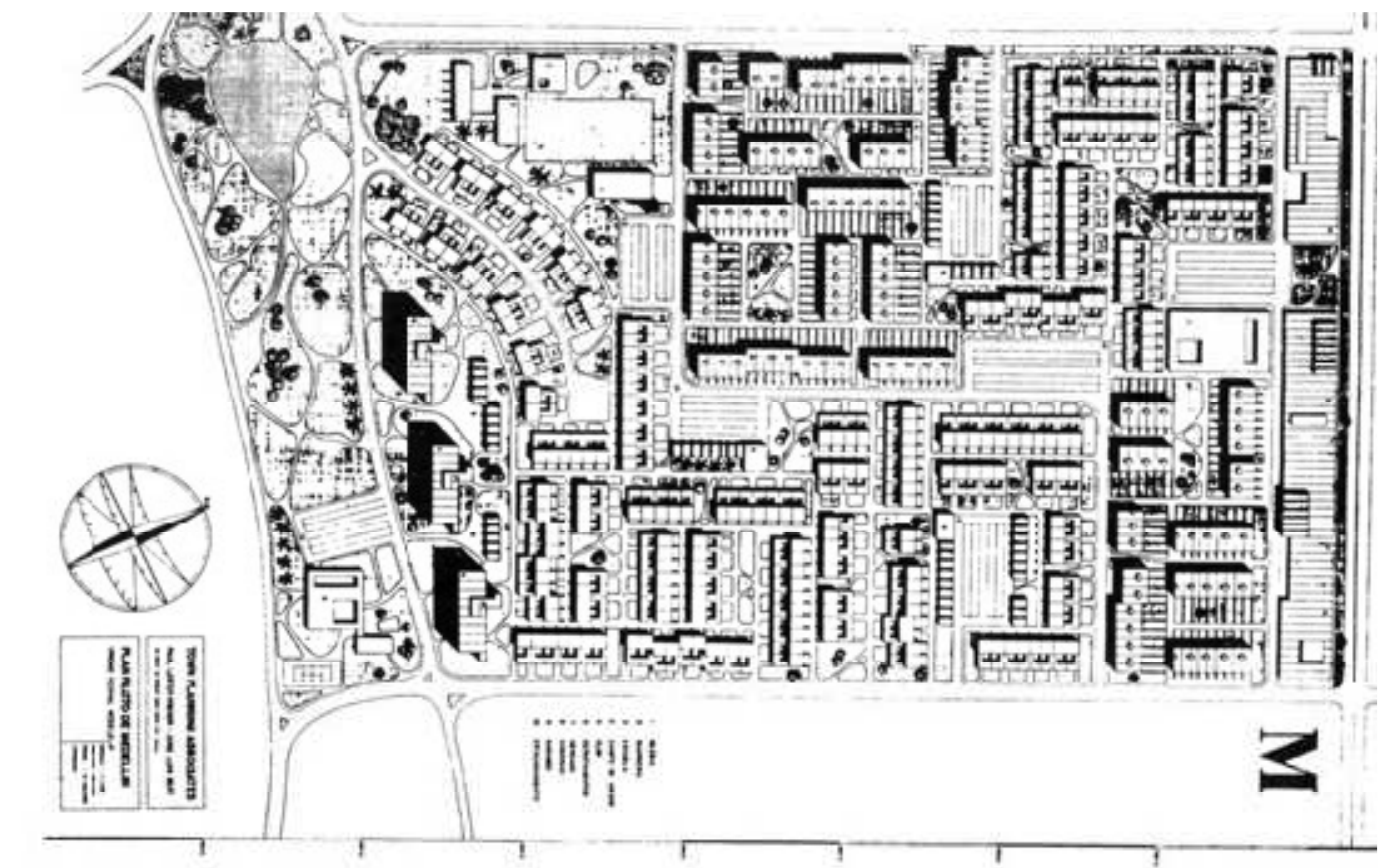

Plane: Oficina de planeación. Medellin

Figura 4. O modelo da "UnidadVecinal".UV, Plan Piloto- Wiener e Sert.

Fonte: Ágora, Universidad Nacional de Colombia". Galeria de imagens.Medellín. 
A partir de 1948 , começou um novo processo de modernização sob a liderança de uns dos representantes mais fiéis do movimento moderno (Sert e Wiener), embora continuasse com um crescimento incontrolado até meados de 1960. Precisamente neste contexto, Le Corbusier, motivado pelo despertar urbano em muitas das cidades latino-americanas, visita Medellín em 1947, participando ativamente na formulação do "Plan Piloto" tentando realizar uma conexão com as propostas precedentes do "Plano de Medellín Futuro", realizadas na primeira metade do século XX.

Com o decreto 1579 de 1942, se dispôs que o "Instituto de Credito Territorial" (ICT) criado em 1939 na capital do país, Bogotá, teria uma seccional em Medellín com capital próprio para o fornecimento de empréstimos para as habitações populares urbanas e a construção dos denominados "Barrios Populares Modernos"(fig. 5) (INURBE, 1996: 282) com base no modelo UV de Sert e Wiener. O acompanhamento de Wiener e Sert desde 1948 a 1953 destacou a importância na intervenção de novas áreas residenciais acompanhadas de outros serviços complementares para a comunidade, momento no qual a participação do "Instituto de Credito Territorial" (ICT) em 1942 com a colaboração de Sert e Wiener como assessores, foi fundamental.

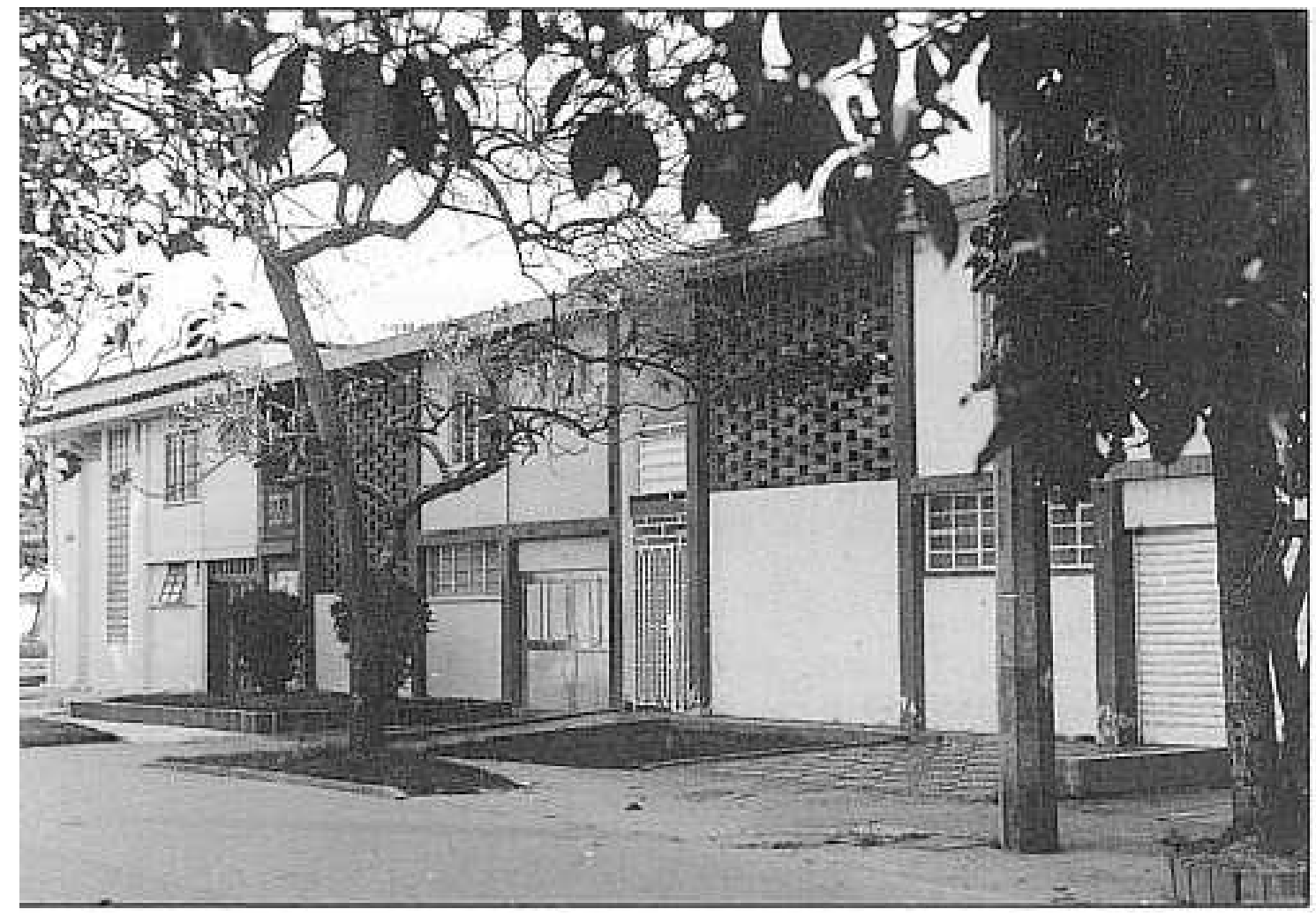

Figura 5. Bairro "Los Libertadores" - Medellín, 1952, executor: ICT.

Fonte: INURBE, 1996, pag. 294. Bairro planejado baixo os princípios da arquitetura moderna para a classe obreira. 
Tentando aplicar algumas considerações urbanas e a construção de bairros modernos segundo o modelo do Plan Piloto, o ICT em 1950 começou a produção em grande escala de habitação com uma fabricação bastante ativa. Produção que se viu ampliada em capacidade operativa com a obtenção de crédito externo por meio da Aliança para o Progresso até 1973, data na qual foram eliminados os aportes externos. Neste período intenso de construção de habitação (1950-1973) do ICT, se cria uma consciência urbanística moderna e a necessidade de pôr procedimentos de construção modernos no canteiro: produção em série, coordenação modular, planificação de obra, especialização da mão de obra, assim como um trabalho pedagógico com o qual se lucraria o setor privado mais adiante (INURBE, 1996: 283). No "Plan Piloto" para Medellín, conquanto definiram-se lineamentos para a construção de habitação em altura, durante os anos próximos a sua formulação,construiu-se somente habitação social unifamiliar com base na proposta para o desenvolvimento de novos bairros; inclusive os próprios projetistas (Wiener y Sert) desenharam unidades residenciais, das quais algumas chegaram a se materializar (fig. 6). Somente em 1961 se construiu o primeiro bairro de edifícios multifamiliares de moradia social em Medellín e, posteriormente, o segundo em 1968, nos quais se tentou introduzir um máximo de economia formuladas de acordo com as normas mais avançadas do urbanismo moderno. Estas duas experiências de habitação social multifamiliar resultaram em uma base experimental para a consolidação de futuros projetos e principalmente para o fortalecimento de uma normativa que permitisse regular este tipo de edificação. Este período, portanto, corresponde não só à implantação de princípios dirigidos ao planejamento urbano, mas também, a um processo de modernização da habitação, principalmente para o que foi dirigida pelo Estado.

A partir de 1968 começaram a se produzir as primeiras regulamentações (Lei 66 de 1968) com o intuito de controlar e orientar o desenvolvimento urbano da cidade, controle que até o momento era muito fraco e anárquico. As primeiras regulamentações para controlar a atividade construtora na cidade foram assinaladas como segregacionistas, já que na prática distinguiam a cidade em três grandes estratos socioeconômicos: as classes alta, média e baixa. Estatuto que permaneceu vigente até 1972, data na qual a prefeitura decidiu aplicar as recomendações de um estudo contratado por eles mesmos, reconhecido como "Normas Mínimas de Urbanización" (INURBE, 1996: 276-277). No espaço para a elaboração 
destanormativa são pensadas as primeiras aproximações para a construção e financiamento de habitação multifamiliar.

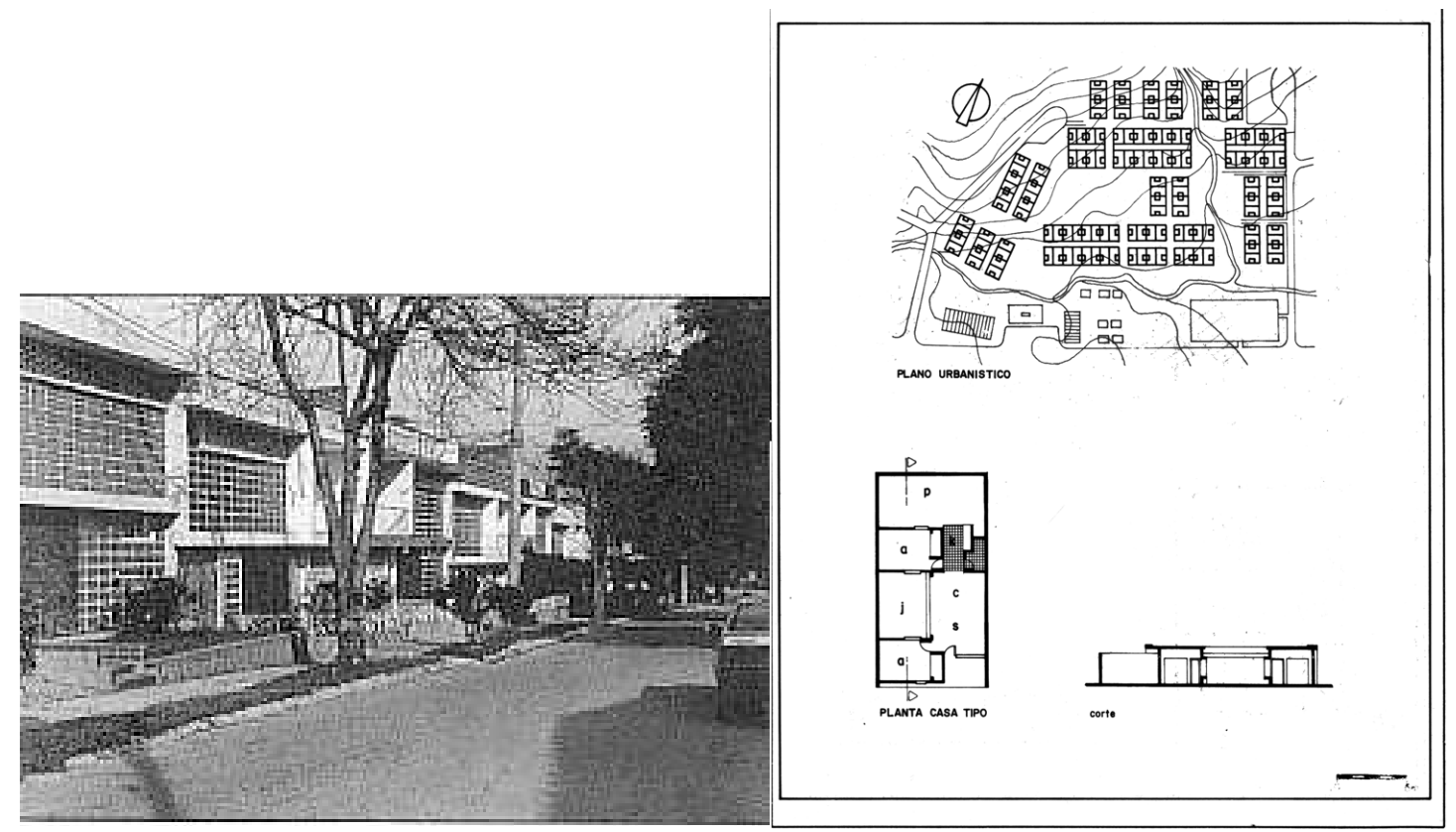

Figura 6. Conjunto residencial "Alcazares", Medellín-Colômbia. Obra de Wiener e Sert, 1951. Fonte: INURBE 1996 pag. 313.

Nos primeiros anos da década de 1970, Medellín se apresentava como uma cidade com bairros de habitação unifamiliar, porém advertia sérios problemas para futuras áreas de expansão, pelo que começou a necessidade de adensar a cidade.

Esta situação levou a Municipalidade a modificar os setores residenciais que estavam destinados à moradia de um ou dois pavimentos no Plano Regulador de Wiener e Sert, por uma regulamentação que permitisse a construção de edifícios tipo apartamento.Situaçãoconcretizada no planejamento das "Normas Mínimas de Urbanización" com o surgimento das primeiras normativas de edificações em altura e assim responder à necessidade de aumentar o processo de densificação na cidade; normativa que permitiu que muitos dos grandes programas habitacionais do Estado pudessem se materializar.Em 1972 a cidade de Medellín só contava com alguns edifícios privados, resultado da especulação imobiliária, localizados geralmente de maneira estratégica no centro da cidade. Portanto, os habitantes desta cidade em crescimento não contavam com a experiência de viver em edificações tipo apartamento, enfrentando uma nova forma de habitar, cenário de muito interesse para desenvolver em outro momento. Esta nova forma de habitar, lentamente foi acolhida pelos novos usuários estendendo-se de maneira gradual às classes alta e média, até ser aceito e massificado por grupos proletários e populares. 
Durante este período, para a formulação das "Normas Mínimas de Urbanización", o ICT põe em práticatanto as recomendações da experiência internacional desde 1950, especialmente com a missão CEPAL (1958), Currie (1961) e o "Plan Piloto de Wiener y Sert "(1958). Mas no caso particular de Medellín, foram adotadas as recomendações dos princípios da arquitetura e urbanismo moderno do "Centro Interamericano de La Vivienda"- CINVA. O CINVA foi criado no ano 1952 em Bogotá, aparição que coincidiu com as propostas do Padre Lebret, liderando várias experiências de participação com as comunidades, especialmente as relacionadas com a assessoria técnica para a autoconstrução e a autoajuda (Peña, 2008: 188-189).

Desta experiência surgiram diferentes linhas de ação nacionais para a adoção de programas de autoconstrução financiadas por meio da cooperação da Aliança para o Progresso com especial atenção para a classe obreira com o intuito de baixar o preço da habitação, erradicar tugúrios e bairros subnormais e contribuir com a valorização do solo por fora do perímetro urbano. A contribuição do programa "Plan Terceras Partes"(P3), por exemplo, que consistia na participação econômica de três atores com porcentagens iguais: a família, uma entidade privada e o ICT, contribuíram para este propósito de maneira que fizeram possível uma melhor obtenção de créditos e empréstimos externos (Ceballos: 2008: 95-102).

Nesta fase, inclusive até começos dos anos 1980, encontramos edificações simples, com uma arquitetura fora da espetacularização, dotada de uma qualidade espacial que até hoje continua sendo altamente valorizada no mercado imobiliário. A moradia desenvolvida neste período é o fiel legado do pensamento moderno tanto da forma urbana quanto da própria habitação.

A partir de 1972 podemos considerar a produção de moradia social como um momento de decadência. Com o acelerado crescimento da população no fim dos anos 1980 e começo dos 1990, se pretendeu diminuir o déficit da habitação já acumulado na cidade, mediante uma estratégia de construção massiva de habitações baratas, com especificações mínimas em todos os níveis: urbanístico, arquitetônico e construtivo (INURBE, 1996: 286); o que trouxe como consequência o empobrecimento de uma habitação que diminuiu radicalmente sua qualidade arquitetônica, atributo que havia caraterizado as obras de habitação social produzida pela Municipalidadee principalmente pelo ICT. Desta forma começou uma diminuição na produção de moradia Estatal, enquanto aumentava a participação do setor privado como resposta à deficiente gestão governamental. 
O ICT e outras instituições que aportaram à consolidação da habitação moderna ficaram reduzidas simplesmente a uma supervivência burocrática, somado ao seu enfoque populista com produção de habitação completamente descontextualizada e de má qualidade tanto interior quanto urbana. Mas este tema deve ser analisado em outro momento, correspondente à crises pós-moderna da moradia em Medellín.

\section{Reflexões finais}

- Das missões:

Embora o tema das missões econômicas internacionais não foi amplamente colocado no texto,é importante fazer um comentário final ao respeito. As missões internacionais indiscutivelmente se convertem em um dos assuntos mais importantes para compreender o desenvolvimento da habitação social moderna na Colômbia. O trabalho de agentes externos, em uma época na qual era muito difícil obtero conhecimento, permitiu que um maior número de profissionais recém-formados em diversas disciplinas, puderam aderir essa informação técnica, social e cultural; contando com funcionários públicos altamente capacitados nas instituições estataisAs recomendações realizadas pelos diferentes conselheiros favoreceram o processo de modernização da política econômica do país e das instituições, refletido naelaboração de políticas urbanas e na consolidação de cidades modernizadas.

Em que pese as missões terem chegadoem situações conjunturais, as recomendações finais dos assessores devem ser entendidas por fora das crises de cada país, que em nosso caso, Colômbia, tiveram um forte conteúdo estrutural em diversas áreas, mas principalmente macroeconômico, e os seus resultados foram evidentes só a longo prazo. Por exemplo, de não se ter aplicado no país uma estratégia macroeconômica baseada na construção de moradias urbanas, provavelmente a marginalidade e a informalidade houvessem alcançado níveis muito mais preocupantes como os que apresentam outros países que têm um desenvolvimento similar ao nosso.

Com respeito às instituições, este período (1942-1972) se caracterizou por um predomínio do governo nacional como ator, principalmente por meio do Instituto de Credito Territorial e do Banco Central Hipotecario, concentrando a oferta de habitação para lares com ingressos médios e baixos facilitando o aceso à propriedade da mesma.

- Do enquadramento da casa como mercadoria 
As caraterísticas da casa moderna na Colômbia,modeladas pelos legados europeus, indiscutivelmente são consideradas um bem de alta qualidade espacial e urbana. Apesar das críticas feitas à arquitetura moderna como resultado de uma materialização que não tem presentes muitas condições humanas pelas suas aproximações como máquina, produção em série, racionalismo, dentre outros aspetos; os resultados formais oferecem uma concretização equilibrada entre homem e espaço. Com o despegue do desenvolvimento capitalista em nosso país, as necessidades habitacionais em termos de déficit obrigaram que estas casas de caraterísticas próprias, fora da espetacularização pela sua simplicidade, tivessem que se enquadrar no âmbito da acumulação do capital. Dito enquadramento, para nosso caso,aconteceu principalmente por meio da estrutura financeira do setor da construção como motor de desenvolvimento econômico. De tal forma, a casa afastouse da sua significação como bem básico com relação ao ser, para receber um tratamento de mercadoria e bem de investimento e com estesinúmerososusos do seu interior pautados pelas regras capitalistas.

Aqui consideramos o ponto de ruptura com a anterior política: de produtor à interventor, o Estado deixouas responsabilidades de produtor no mercado e na qualidade da habitação, para se tornar um simples interventor. Por isso, no início da década de 1980 as metas numéricas se converteram no principal objetivo, perdendose de focoo usuário, a comunidade, o bairro, a cidade.

- o caso de Medellín: a habitação moderna e o seu processo de perda de habitabilidade.

Embora existam antecedentes de processos de renovação urbana a partir de 1890 com o "Plan para elEnsanchamiento Futuro de laCiudad" e em 1913 com o plano de "Medellín Futuro"indicando reflexões temporãs, o caso de Medellín não se afasta dos acontecimentos urbanos ocorridos no panorama nacional. Estas propostas iniciais permitiram possibilidades de novas maneiras de pensar a cidade e começar uma nova fase no desenvolvimento urbano, assim como a disposição mental para a recepção as propostas e ideias urbanas desenvolvidas a partir de 1940: Wiener e Sert e o seu "Plan Regulador", as missões internacionais da Europa e Estados Unidos (Kemmerer, Lebret, Cepal, Currie), o CINVA, a criação de instituições como o "Instituto de Credito Territorial" e o "Banco Central Hipotecario" e, com todos eles, a modernização da cidade.

As materializações, resultado dos aportes internacionaise institucionais,pretendiam,depois da segunda metade do século $X X$, solucionar 
inumeráveis problemas de circulação, mobilidade, uso do solo, carência de zonas verdes, especulação de terrenos, acesso à habitação, entre outros aspetos; muitos dos quais foram resolvidos com ajuda destas contribuições.

O ator mais importante na produção de habitação social na cidade de Medellín foi indiscutivelmente o ICT, o qual, a partir de 1950 começou umaprodução em grande escala com uma fabricação bastante ativa e de altíssima qualidade embora se tratasse moradia para a classe obreira. Foi a instituição que materializou uma consciência urbanística moderna na cidade e pôs em andamento procedimentos de construção modernos: produção em série, coordenação modular, planificação de obra, especialização da mão de obra. E um dos assuntos de maior aporte, um trabalho pedagógico para o desenvolvimento futuro da cidade nas mãos de agentes privados.

O processo de decaimento da habitação, produto do crescimento capitalista na cidade e quecomeçou depois da segunda metade de 1970, implementou uma série normativa debenefíciosaos particulares, que levou não só a cidade a uma queda em termos urbanos, mas a habitação entrou em um processo de deterioração que perdura até os presentes dias.

O acelerado progresso de habitação não foi próprio de Medellín, mas teve ocasiões em cidades Colombianas e latino-americanas onde se experimentaram fenômenos similares. De tal forma, que os aportes deste texto pretendem, entre outros aspectos, o reconhecimento e cruzamentos de características comuns dentro de projetos de pesquisa que abordem uma perspectiva latino-americana. A partir da experiência deste trabalho, fica aberta a possibilidade de se aprofundar em uma verificação dos comportamentos de outros países latino-americanos com relação aos processos de modernização urbana referentes à produção de habitação social.

Por meio da elaboração deste texto, se pôde delimitar os interesses e o marco espaço-temporal da pesquisa.Interessa majoritariamente, como já indicado, os acontecimentos apresentados entre 1940 e 1972; momento pleno da produção de habitação moderna em Medellín. Medellín nesta época passou uns dos mais interessantes processos em termos de produção de habitação social, evidenciaram-se representações de moradias herdadas das reflexões da arquitetura moderna, as quais passaram por um processo de apropriação e expressão próprias de uma cidade com fortes marcas rurais e camponesas;até o surgimento da habitação multifamiliar, que trouxe consigo uma nova forma de habitar e com esta o nascimento de uma nova metrópole. 


\section{Referências}

BEJARANO, Jesús A (1978). Industrialización y política económica (1950-1976), Bogotá: ed. Arrubla.

BETANCUR, Agapito (1925). La ciudad: Medellín en su $5^{\circ}$ cincuentenario de su fundación, Medellín: Ed. Bedout.

CEBALLOS Ramos, Olga Lucia (2008). Vivienda Social en Colombia: una mirada desde su legislación 1918-2005. Bogotá: Pontificia Universidad Javeriana.

FIQUE, P. Luis Fernando (2006). Vivienda social em Colombia. Políticas publicas y habitabilidad en los años 90. Bogotá, Universidad Nacional de Colombia: Ed. Punto Aparte.

GONZÁLEZ, Escobar, Lius Fernando (2007). Medellín. Los orígenes y la transición a la modernidad: Crecimiento y modelos urbanos 1775-1932. Medellín-Colombia. Escuela del Hábitat CEHAP, Facultad de Arquitectura: Universidad Nacional de Colombia.

INURBE (1996), Estado, Ciudad y Vivienda. Urbanismo y arquitectura da la vivienda estatal en Colombia, 1918-1990. Bogotá.

MONSALVE, Manuel (1954). Colombia, posesiones presidenciales 1810-1954. ed. Bogotá:Iqueima

PALACIOS, Marco;FrankSafford (2002). Colombia: país fragmentado, sociedad dividida, su historia. Bogota: Ed Siglo XXI.

PEÑA Rodríguez, Martha Liliana. El Programa CINVA y la acción comunal. Revista Bitácora Urbano Territorial [en línea] 2008, vol. 12 [citado 2012-12-06]. Disponible en Internet: http://redalyc.uaemex.mx/src/inicio/ArtPdfRed.jsp?iCve=74811916012 data de consulta: dezembro 6 de 2012.

SCHNITTER Castellanos, Patricia (2003). La vivienda social en la aplicación del urbanismo moderno. En: Scripta Nova-Revista Electronica DeGeografia Y Ciencias Sociales. Universidad De Barcelona Vol.VII fasc.146.

SINGER, Paul (1995). Economia politica da urbanização. São Paulo: Editora Brasilense S.A.

SINGER, Paul (1979); O uso do solo urbano na economia capitalista, em: MARICATO, Ermínia - (Org.): A produção capitalista da casa (e da cidade) no Brasil industrial. São Paulo: Alfa-omega. 